\title{
Absorption Spectra of Natural Dyes and Their Effect on Efficiency of ZnO Based Dye-Sensitized Solar Cells
}

\author{
I.B. Karki ${ }^{1,2}$, J.J. Nakarmi ${ }^{1}$, P.K. Mandal ${ }^{2}$ and S. Chatterjee ${ }^{2}$ \\ ${ }^{1}$ Central Department of Physics \\ Tribhuvan University \\ Kirtipur, Kathmandu \\ ${ }^{2}$ Department of Physics \\ University of North Bengal \\ Siliguri-734013, India \\ e-mail: indrakarky@gmail.com
}

\begin{abstract}
Natural dye-sensitized solar cells (DSSC) are one of the most promising devices for the solar energy conversion due to their low production cost and low environmental impact. The synthesis and performance study of Zinc oxide ( $\mathrm{ZnO})$ nanorods based DSSC is reported in the present paper. $\mathrm{ZnO}$ nanorods were fabricated using sol-gel spin coating process and different types of DSSCs were fabricated using two different classes of natural dyes, xanthenes, anthocyanins and a mixed-dye with equal proportion mixture of xanthenes and anthocyanins. The ultravioletvisible (UV-Vis.) absorbance spectra were compared with performances of the cells. Efficiency of fabricated cells and cell characteristics were found to be related with absorption spectra of dyes.
\end{abstract}

Key words: absorption spectra, dye-sensitized solar cell, efficiency, natural dyes, ZnO nanorods.

\section{Introduction}

Conversion of solar-energy and electric-energy storage are becoming most import techniques towards issues on energy crisis and sustainable use. For the solar-energy conversion, as mostly by the form of crystalline solar cell, DSSCs with nanocrystalline ceramics, dye molecules, and electrolytes are recently developed for light harvesting (Gratzel 2003,Tennakone et al 1996). DSSCs are a promising low cost, green energy source ( Hao et al. 2006, Amao et al. 2004). A power conversion efficiency of $11.18 \%$ has been achieved (Gratzel 2003). DSSC is a device for the conversion of visible light into electricity.

Solar cell production has grown at about 30\% per annum over the past 15 years. In recent years, great attention has been paid to DSSCs due to their low fabrication cost as a viable alternative technology for renewable energy (Gratzel 2003). It has attracted much attention due to its environment friendly nature, high efficiencies and potentially low production costs. Organic dyes have been intensively investigated due to their potential use in various low-cost, large area DSSC applications. (Pradhan 2007, Pradhan et al. 2004)

Normally Titanium dioxide $\left(\mathrm{TiO}_{2}\right)$ nanostructures are used to fabricate DSSC. However, $\mathrm{ZnO}$ has shown a great deal of research interest in DSSCs due to some of its fascinating properties. $\mathrm{ZnO}$ is often utilized as a photo anode material in DSSCs due to its properties such as large exciton binding energy, wide direct band gap of $3.27 \mathrm{eV}$, which is generally used in organic solar cells (Gratzel 2003,Tennakone et al. 1996).

$\mathrm{ZnO}$ is also highly transparent, which allows for greater light penetration. Finally, 1-D single crystal structure formation is possible with $\mathrm{ZnO}$, enabling a higher surfaceto-volume ratio for greater dye loading.

To increase the conversion efficiency of $\mathrm{ZnO}$ nanorodbased DSSCs, it would be desirable to eliminate the interface between Indium doped Tin oxide (ITO) and the ZnO nanorods (Pradhan et al. 2004, Tsubomura et al.1976, Terahara et al. 1990 and Bandhopadhyay et al. 2003). Some researchers (Chen et al 2008) have recently taken up this concept by growing $\mathrm{ZnO}$ nanorods on a $\mathrm{ZnO}$ film 
using a two-step method. In this work $\mathrm{ZnO}$ nanorods were grown on an ITO coated glass using sol-gel spin coating technique.

The absorption spectrum of the dye and the anchorage of the dye to the surface of $\mathrm{ZnO}$ are important parameters determining the efficiency of the cell. Generally, transition metal coordination compounds (ruthenium poly-pyridyl complexes) are used as the effective sensitizers, due to their intense chargetransfer absorption in the whole visible range and highly efficient metal-to-ligand charge transfer (Duffy et al. 2000, Gratzel 2001 \& Law et al. 2005). However, ruthenium polypyridyl complexes contain a heavy metal, which is undesirable from point of view of the environmental aspects and high cost (Amao \& Komori 2004). Moreover, the process to synthesize the complexes is complicated and costly. Alternatively, natural dyes can be used for the same purpose with an acceptable efficiency (Pradhan et al. 2007, Polo and Iha 2006, Garcia et al. 2003, Smested 1998 and Cherapy et al. 1997). The advantages of natural dyes include their availability and low cost (Cherapy et al. 1997). The sensitization of wide bandgap semiconductors using natural pigments is usually ascribed to anthocyanins. This makes electron transfer from the anthocyanins molecule to the conduction band of $\mathrm{ZnO}$ (Garcia et al. 2003). As reported (Pradhan et al. 2007, Cherapy et al. 1997), anthocyanins from various plants gave different sensitizing performances. However, there is no acceptable explanation behind these results, so far. A natural organic dye, pomegranate juice (Punica Granatum $L$.) is a common source of anthocyanin and is commonly used for fabricating DSSCs.

Rose Bengal dye is one of the best photo sensitizers for $\mathrm{ZnO}$ photoanode to date and is much cheaper than Ru-complex dyes (Nazeeruddin et al. 1993). It is in xanthene class which absorbs wide spectrum of solar energy and energetically matches the $\mathrm{ZnO}$ and usual KI-I $\mathrm{I}_{2}$ redox couple for DSSCs applications (Duffy et al. 2000).

The performance of DSSCs using the mixed xanthene dyes was also investigated by some earlier workers (Gerischer et al. 1968, Watanabe et al. 1976). Two xanthene having different absorption characteristics would give even more synergistic effect compared to the mixed xanthene-chlorophyll dye was reported (Pradhan and Bandhopadhyay 2004). This is because xanthene has advantages over chlorophyll as DSSC sensitizer (Cherepy et al. 1997). Two kinds of dyes, namely, metal-organic complexes (e.g., Ru-complexes) (Frank 2005) and metal-free organic dyes, (Gerischer et al. 1968, Watanabe et al. 1976, Islam et al. 2001) have been widely used as sensitizers of DSSCs. Organic dyes have several advantages as photo sensitizers for DSSCs: (1) Larger absorption coefficients than metal-complex photo sensitizers; (2) variety in their structures provides possibilities for molecular design, e.g., the introduction of substituent, and thus allows for easy control of their absorption spectra; (3) inexpensive because they do not contain noble metals like ruthenium. This reduces the overall cost of the cell production.

In this study, a natural organic dye of class Anthocyanin, pomegranate juice was investigated in fabricating ZnO nanorods based DSSCs as these dyes are abundant in tropical countries (Nazeeruddin et al. 1993) which resulted in low fabrication cost. Another cell is fabricated with Xanthene class of dye, Rose Bengal, and a third cell was fabricated with a mixed Dye prepared by mixing equal proportions of Rose Bengal and Pomegranate juice. Finally, the qualities of the fabricated cells were investigated in terms of standard cell parameters including its conversion efficiency. The effects of dyes are discussed in terms of their UV-Vis. absorption spectra.

\section{Methodology}

$\mathrm{ZnO}$ nanorods were synthesized using sol-gel method and fabricated using spin coating technique. Spincoating is a simple method for preparing znO nanoseed from zinc acetate solution. In this process, we prepared $5 \mathrm{mM}$ solution of Zinc acetate dehydrate $\left(\mathrm{CH}_{3} \mathrm{COO}\right)_{2} \mathrm{Zn}, 2 \mathrm{H}_{2} \mathrm{O}$, (98\% Merck) was prepared with methanol. The solution was spun on indium tin oxide (ITO)-coated glass substrates at $1000 \mathrm{rpm}$ for 30s. The zinc acetate solution was spread on a rotating substrate (Pradhan et al. 2007, Cherepy et al. 1997). The substrates were heated to $350{ }^{\circ} \mathrm{C}$ in conventional oven for $30 \mathrm{~min}$ to yield layers of $\mathrm{ZnO}$ islands with their (100) plane parallel to the substrate surface. After evaporation of solvent, a thin $\mathrm{ZnO}$ film was formed. Repetition of the above process 5 to 7 times was carried out to control the thickness of the film. Concentration of the solution and spinning speed of the substrate also played important roles in adjusting the thickness of the fabricated film. The counter electrode (cathode) was prepared on another ITO coated glass by using carbon dust. 


\section{Characterization of dye and Dye Deposition}

The device was then immersed in a solution of sensitized dye for 24 hours to allow the dye molecules to form covalent bond to the surface of the $\mathrm{ZnO}$. The samples were then rinsed with ethanol to remove excess dye on the surface and air-dried at room temperature. The absorption spectra of dyes were recorded using a UVVis spectrophotometer (Perkin Elmer Lamda-35 model UVVis).

\section{DSSC assembling}

DSSCs were assembled following the procedure described in the literature (Pradhan et al. 2007). The carbon dust coated counter electrode was placed on the top so that the conductive side of the counter electrode faces the $\mathrm{ZnO}$ film. The iodide based solution as the liquid electrolyte (0.5M potassium iodide mixed with $0.05 \mathrm{M}$ iodine in water-free ethylene glycol) was placed at the edges of the plates. The liquid was drawn into the space between the electrodes by capillary action. Two binder clips were used to hold the electrodes together.

\section{Device Characterization and Measurement}

\section{Apparatus setup}

Keithley model 2400 digital source pico-ammeter was used to measure the dark and illuminated $I-V$ characteristics of the DSSC under white light illumination (Xenon-lamp) conditions for the efficiency calculation. The position of the light source was adjusted such that the light intensity was $100 \mathrm{~mW} /$ $\mathrm{cm}^{2}$ (equivalent of one sun) at AM 1.5. The currentvoltage characteristics of DSSCs under various light intensities were obtained.

\section{Characteristics of dye-sensitized solar cells}

The current-voltage characteristics of a cell in the dark and under illumination permit an evaluation of most of its photovoltaic performances as well as its electric behavior (Rostalski \& Meissner 2000).

The short circuit current $\left(\mathrm{I}_{\mathrm{sc}}\right)$ is the one which crosses the cell at zero applied voltage and it is a function of illumination. Charges travel under an internal potential difference typically equal to open circuit voltage $\left(\mathrm{V}_{\text {oc }}\right)$.

The $\mathrm{V}_{\text {oc }}$ is measured when current in the cell is 0 , corresponding to almost flat valence and conduction bands; $\mathrm{I}_{\max }$ and $\mathrm{V}_{\max }$ values are defined in order to maximize the power $\left|\mathrm{I}_{\max } \times \mathrm{V}_{\max }\right|$. This is the maximum power $\mathrm{P}_{\max }$ delivered by the cell. The fill factor FF is the ratio of the maximum power to product of short circuit current and open circuit voltage.

$$
F F=\frac{P_{\max }}{V_{o c} \times I_{s c}}=\frac{I_{\max } \times V_{\max }}{I_{s c} \times V_{o c}}
$$

The external photovoltaic yield or efficiency ç is defined as the ratio of the maximum electric power extracted to the illumination times the surface area, i.e. $\mathrm{P}_{\text {in }}$ of the cell:

$$
\eta=\frac{\left[V_{O C} \times I_{S C} \times F F\right]}{\left[P_{i n}\right]} \times 100 \%
$$

(It is often expressed as a percentage). Conversion yield is the key parameter as concerns cells productivity (Rostalski and Meissner 2000).

\section{The equivalent circuit model of DSSC}

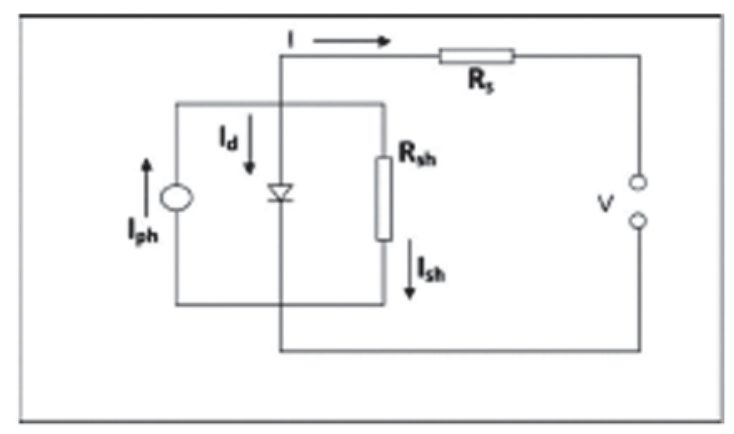

Fig. 1 Equivalent Circuit Diagram of DSSC

A solar cell is generally characterized using the equiv lent circuit of the single diode model as shown in Figure 1 and the relation between the current $I$ and the voltage $V$ is given by

$I=I_{p h}-I_{s}\left[\exp \left\{\frac{q\left(V+R_{s} I\right)}{A k_{B} T}\right\}-1\right]-\frac{V+R_{s} I}{R_{s h}}$

where $I_{p h}, I_{s}, R_{s}, R_{s h}, q, A, k_{B}$, and $T$ are the photocurrent, the saturation current of the diode, the series resistance, the shunt resistance, the electron charge, the ideality factor, the Boltzmann constant, and absolute temperature, respectively.

\section{Results and Discussion}

\section{Structure characterization}

The morphology of the samples was observed using a scanning electron microscope (SEM) with a field emission gun operating at $200 \mathrm{kV}$. Figure 2a displays $\mathrm{ZnO}$ nanowire arrays in a wide surface area. The nanorods have an average length of $600 \mathrm{~nm}$, diameter 
ranging from 100 to $200 \mathrm{~nm}$ and they are mostly vertically aligned with the substrate having hexagonal shapes. Figure 2b shows hexagonal shapes of $\mathrm{ZnO}$. The thickness of $\mathrm{ZnO}$ film was around $\sim 2 \mathrm{im}$.

The nanowires, which make barrier free contact with the substrates, exhibit resistivity around 0.3 to $2.0 \mathrm{Wcm}$ along the long axis (Islam et al. 2001). The nanowire used in the present work had a resistivity $0.7 \mathrm{Wcm}$ at $0 \mathrm{~V}$. Due to absence of interfaces in nanowires, resistivity of a nanowire should be lower than nanoparticle thin films. Moreover, conductivity in the nanowire arrays increase by 5 to $20 \%$ when they are soaked in standard DSSC electrolytes (Islam et al. 2001).

In general, the energy conversion efficiency of $\mathrm{ZnO}$ based DSSCs is lower than that of $\mathrm{TiO}_{2}$ based DSSCs (Fran 2005, Nazeeruddin et al 1993, Islam et al. 2001). However, due to the barrier free contact, $\mathrm{ZnO}$ nanowire is expected to give higher efficiency. Because only about $4 \%$ of the solar spectrum falls in the UV region, $\mathrm{ZnO}$ semiconductor absorbs solar radiation while sensitized by natural dye molecules with absorption spectra at visible region.

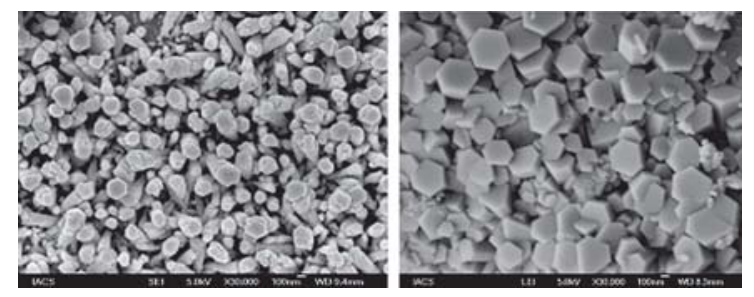

Fig. 2. Scanning electron microscopic (SEM) micrographs of $\mathrm{ZnO}$ nanorod used in the dye-sensitized solar cell

$\backslash$ Anthocyanin dyes present in Pomegranate Fruits are responsible for absorption of solar energy Miguel $e t$ al. 2004). Anthocyanin dye is responsible for several colors in the red-blue range depending on $\mathrm{pH}$ value. The red anthocyanin absorbs at $530 \mathrm{~nm}$ (band gap 2.3 $\mathrm{eV}$ ), whereas, Rose Bengal has got a Xanthene class of dye with a band gap $1.9 \mathrm{eV}$ and maximum absorption peak at $555 \mathrm{~nm}$.

After absorbing photon energy from the illuminated white light, the dye molecules in the DSSCs become excited and inject electrons to the $\mathrm{ZnO}$ nanowires (Fig. 3). Due to favorable energy difference, electron transfer occurs between the lowest unoccupied molecular orbital (LUMO) of the dye and the conduction band of $\mathrm{ZnO}$. The photogenerated electrons percolate rapidly through the $\mathrm{ZnO}$ nanowire and are collected by the conducting glass support. The highest occupied

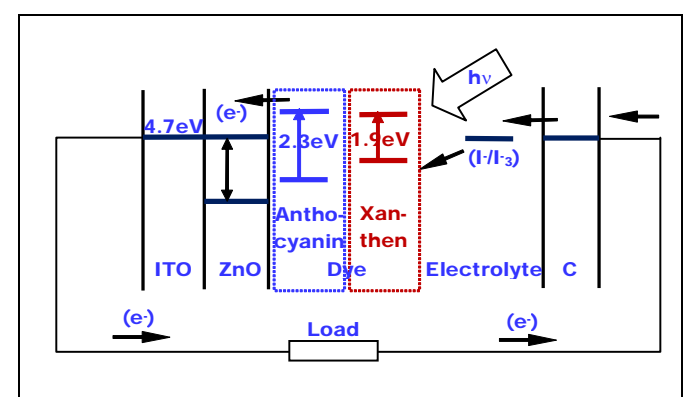

Fig. 3. Schematic band diagram showing the working principle of DSSC with various dyes

molecular orbital (HOMO) of the dye is energetically lower than the redox potential, $\mathrm{E}_{\text {redox }}$ of the iodine/ triiodide couple. The energy difference provides the driving force for hole injection into the electrolyte. Recombination of charge carrier is also minimized in such devices since transport of only one type of carrier (electron, in general) is energetically possible from the dye to the semiconductor. For Rose Bengal dye (Xanthenes), the energy difference is $1.9 \mathrm{eV}$ (Pradhan et al. 2004) and for pomegranate (Anthocyanins) the energy difference is $2.3 \mathrm{eV}$ (Miguel et al. 2004).

\section{Characterization of dyes}

Three organic dyes which are commonly used to sensitize the semiconductor layer in DSSC are Rose Bengal, Pomegranate and Mixed Dye having absorption peak at 555, 525, and $545 \mathrm{~nm}$, respectively as shown in Fig. 4. These dyes suffer from the fact that individually they absorb very small portion of the visible spectrum of solar radiations giving rise to a low efficiency of DSSCs. The peak of the absorption spectra of the dyes are in tune with HOMO-LUMO energy difference of Xanthene and Anthocyanin class of dye.

Since no single dye can perform efficiently in the entire visible spectrum, the present work is focused on the performance study of I-V curve of DSSCs with various dyes having broadband absorption in the visible spectrum for efficient harvesting of light by DSSCs. The Rose Bengal dye absorbs a larger fraction of the solar spectrum in the visible region $460-650 \mathrm{~nm}$. The Rose Bengal dye has been used to sensitize $\mathrm{ZnO}$ electrode of the DSSCs. On the other hand Pomegranate is a natural dye with wider absorption peak at lower wavelength range of solar spectrum. The spectrum of mixed dye shows even wider absorption band and is expected to harvest more solar energy. 


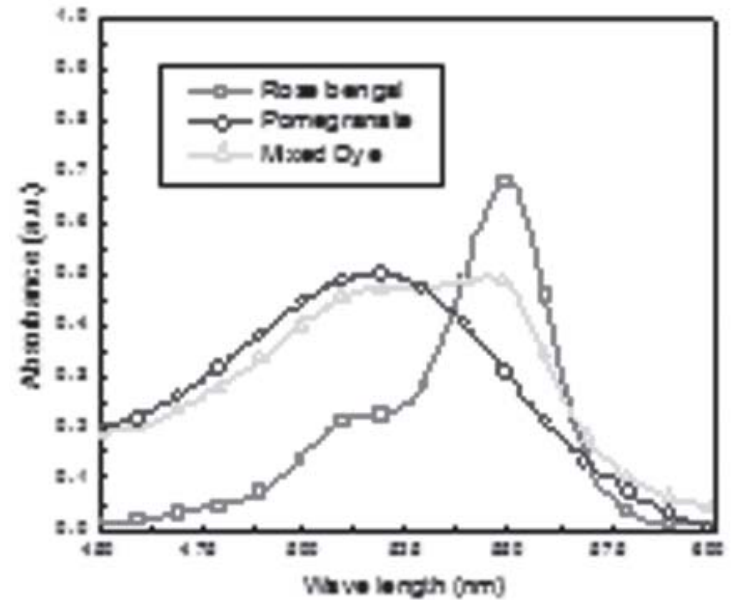

Fig. 4. Absorption spectra of Rose Bengal, Pomegranate and Mixed dye

We have recorded $I-V$ characteristics of $\mathrm{ZnO}$ nanorods based DSSCs using Rose Bengal, Pomegranate (Punica Granatum) and Mixed dye with equal proportion mixture of these two, with varied external resistances under illumination.

Figure 4 shows the current voltage curves of various dyes based DSSCs. The Rose Bengal dye shows highest short circuit current whereas Pomegranate has lower value of both open circuit voltage and short circuit current. However, the mixed dye showed highest open circuit voltage with appreciable short circuit current.

\section{Photovoltaic properties}

The $\mathrm{V}_{\mathrm{oc}}, \mathrm{I}_{\mathrm{sc}}$, voltage at maximum power $\left(\mathrm{V}_{\mathrm{max}}\right)$, current at maximum power $\left(\mathrm{I}_{\max }\right)$, values of DSSC cells with three different dyes were calculated from Figure 5 and fitted with the Equation 3 for one diode equivalent circuit model (Fig. 1) by Newton-Raphson's method. Results of Curve fitting are given in Table-I.

The parasitic resistances (series and shunt) of DSSCs are important parameters that affect their efficiency. The resulting parasitic resistances, series $\left(R_{s}\right)$ and shunt resistance $\left(R_{\text {sh }}\right)$ were evaluated from these results. Pomegranate has high series resistance, whereas using mixed dye subsequent reduction in series resistance was obtained, which results in substantial improvement in cell performance. From the data of Table-I, it was confirmed that for all kinds of cells, higher the shunt resistance, the efficiency is lowered and efficiency raises with lower series resistances. The fill factor (FF) for all the cells using different dyes are also evaluated from the I-V characteristics using equation (1) and finally the energy conversion efficiency (h) is calculated using equation (2). All these results are presented in Table-I.

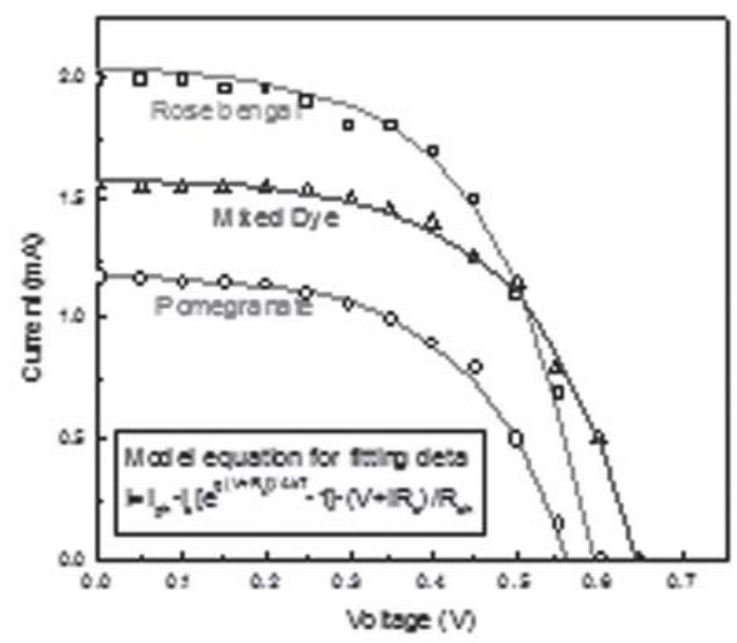

Fig. 5. Current-voltage curves of various dyes based DSSC

All cell parameters like Ideality Factor (A), Fill factor (FF) and Energy conversion efficiency (h) of $\mathrm{ZnO}-$ nanorod-based DSSCs with different dyes are calculated and presented in Table-I where values are calculated from current voltage curves of DSSC cells fabricated with various dyes.

Table I. Solar cell parameters of the three DSSCs

\begin{tabular}{|c|c|c|c|c|c|c|c|c|}
\hline ZnO DSSC Dyes & $\begin{array}{l}V_{o c} \\
(V)\end{array}$ & $\begin{array}{l}I_{s c} \\
(m A)\end{array}$ & $\begin{array}{l}I_{s} \\
(\mu A)\end{array}$ & $\begin{array}{l}R_{s} \\
(\Omega)\end{array}$ & $\begin{array}{l}R_{s h} \\
(\Omega)\end{array}$ & $A$ & $F F$ & $\begin{array}{l}\eta \\
(\%)\end{array}$ \\
\hline Rose Bengal & 0.6 & 2.1 & 13.26 & 0.00308 & 3461 & 4.55 & 0.49 & 1.56 \\
\hline Pome-granate & 0.56 & 1.18 & 9.88 & 0.00489 & 5011 & 4.57 & 0.56 & 1.01 \\
\hline Mixed Dye & 0.65 & 1.57 & 7.96 & 0.00171 & 3934 & 4.73 & 0.54 & 1.41 \\
\hline
\end{tabular}


Nepal Journal of Science and Technology Vol. 13, No. 1 (2012) 179-185

The Rose Bengal dye shows highest efficiency and lowest fill factor, whereas Pomegranate shows lowest efficiency and highest fill factor. Though the mixed dye has an intermediate value of efficiency and fill factor, its values are very close to that of Rose Bengal. So, by mixing two kinds of dyes we achieved very good efficiency, which may be due to exploitation of wider band of energy in the solar spectrum as found out by the UV-Vis. spectroscopic results of the mixed dye. This improvement in efficiency of the mixed dye is due to the improvement in ideality factor. Ideality factor indicates perfectness of the diode in the equivalent circuit, and it is 1.0 for a perfect diode. In our observation an improvement in ideality factor was observed, 4.73 for mixed dye, compared to 4.55 and 4.57 of pure dyes.

$\mathrm{ZnO}$ nanorod based DSSC solar cells were fabricated on ITO coated glass substrate and the cell performance of ZnO-based DSSCs was found out for two types of dyes and also for their mixture. The dyes differ in their absorption spectra and absorb sunlight in different frequency range. The mixed dye with larger band of frequency spectrum shows improvement in efficiency than the average efficiency of the two dyes. This improvement in efficiency of the mixed dye is due to the improvement in ideality factor.

\section{Acknowledgement}

The authors would like to address their thanks to the Central Department of Physics, Tribhuvan University, Kathmandu; North Bengal University, Darjeeling, Siliguri; University Grants Commission (UGC), Nepal; Nepal Academy of Science and Technology (NAST); and Indian National Science Academy (INSA), India, for their financial and technical support for this work.

\section{References}

Amao, Y., T. Komori. 2004. Bio-photovoltaic conversion device using chlorine-e e $_{6}$ derived from chlorophyll from Spirulina adsorbed on a nanocrystalline $\mathrm{TiO}_{2}$ film electrode, Biosensors Bioelectron. 19:843-847.

Bandhopadhyay, A. and A. J. Pal. 2003. Large conductance switching and binary operation in organic devices: Role of functional groups, J. Phys. Chem. B 107:2531-2536.

Chen, H., A. Du Pasquier, G. Saraf, J. Zhong and Y. Lu. 2008. Dye-sensitized solar cells using ZnO nanotips and Ga-doped ZnO films, Semiconductor Science and Technology 23: 1-5.

Cherepy N.J., G.P. Smestad, M. Gratzel and J.Z. Zang.
1997. Ultrafast electron injection: Implications for a photoelectrochemical cell utilizing an anthocyanin dyesensitized $\mathrm{TiO}_{2}$ nanocrystalline electrode, J. Phys. Chem. B 101: 9342-9351

Duffy N.W., L.M. Peter, R.M.G. Rajapakse and K.G.U. Wijayantha. 2000. Investigation of the kinetics of the back reaction of electrons with tri-iodide in dyesensitized nanocrystalline photovoltaic cells, J.Phys.chem. 104: 8916-8919.

Frank, T., M. Janssen, M. Netzel, G. Strass, A. Kler, E. Kriesl and I. Bitsch. 2005. Pharmacokinetics of anthocyanidin-3-glycosides following consumption of Hibiscus sabdariffa L. extract. J Clin Pharmacol, 45: 203-210.

Garcia C.G., A.S. Polo and N.Y. Iha. 2003. Fruit extracts and Ruthenium polypyridinic dyes for sensitization of $\mathrm{TiO}_{2}$ in photoelectrochemical solar cells, J. Photochem. Photobiol. A 160: 87-91.

Gerischer H., M.E. Michel-Beyerle, F. Rebentrost and H. Tributsch. 1968. Sensitization of charge injection into semiconductors with large band gap, Electrochim. Acta 13: 1509-1515.

Graetzel, M. 2001. Photoelectrochemical cells, Nature 114: 338-344.

Gratzel, M. 2003. Dye-sensitized solar cells, J. Photochem. Photobiol. C4: 145-153.

Hao S., J. Wu, Y. Huang, J. Lin. 2006. Natural dyes as photosensitizers for dye-sensitized solar cell, Sol. Energy 80:209-214.

Islam A., H. Sugihara, K. Hara, L.P. Singh, R. Katoh, M. Yanagida, Y. Takahashi, S. Murata and H. Arakawa. 2001. Sensitization of nanocrystalline $\mathrm{TiO}_{2}$ ûlm by Ruthenium(II)diimine dithiolate complexes, $J$. Photochem. Photobiol A 145:135-141.

Law, M., Lori E. Greene, Justin C. Johnson, Richard Aykally and P. Yang. 2005. Nanowire dye-sensitized solar cells, Nat. Mat. 4: 455-459.

Miguel G., C.Fontes, D. Antunes, A. Neves and D. Martins. 2004. Anthocyanin concentration of "Assaria” pomegranate fruits during different cold storage conditions, J. Biomed. Biotechnol. 5: 338-342.

Nazeeruddin M.K., A. Kay, I. Rodicio, R. Humpry Baker, E. Muller, P. Liska, N. Vlachopoulos and M.Gratzel.1993. Conversion of light to electricity bycis-XzBis (2,2'-bipyridyl-4,4'-dicarboxylate)ruthenium (11)Charge-Transfer Sensitizers (X = C1-, Br-, I-, $\mathrm{CN}-$, and $\mathrm{SCN}-$ ) on Nanocrystalline $\mathrm{TiO}_{2}$ Electrodes, J.Am. Chem. Soc. 115: 6382-6390

Nazeeruddin M. K., S.M. Zakeeruddin, R. Humphry-Baker, M. Jirousek, P. Liska, N. Vlachopoulos, V. Shklover, C. H.Fischer and M. Gratzel. 1999. Acid-base equilibria of (2,2-Bipyridyl-4,4-dicarboxylic acid) ruthenium(II) complexes and the effect of protonation on charge-transfer sensitization of nanocrystalline 
titania, Inorg. Chem. 38 (26): 6298-6305.

Peter, L. 2009. “Sticky electrons” transport and interfacial transfer of electrons in the dye-sensitized solar cell. ACCOUNTS of Chemical Research 42: 1839-1847.

Polo, A.S. and N.Y. Iha. 2006. Blue sensitizers for solar cells: Natural dyes from Calafate and Jaboticaba, Sol. Energy Mater. Sol. Cells 90:1936-1944.

Pradhan, B. , S. Kumar, B. Amal and J. Pal. 2007. Vertically aligned $\mathrm{ZnO}$ nanowire arrays in Rose Bengal-based dye-sensitized solar cells, Sol. Energy Mater. Sol. Cells 91:769-773.

Pradhan, B., A. Bandyopadhyay and A.J. Pal. 2004. Molecular level control of donor/acceptor heterostructures in organic photovoltaic devices, Appl Phys. Lett. 85:663.

Rostalski, J. and D. Meissner. 2000. Monochromatic versus solar efficiencies of organic solar cells Solar Energy Mater. Solar Cells 61:87-95.

Sicot, L. 1999. Etude et realisation de cellules photovoltaiques en polymere. Ph. D. Thesis Orsay University, Paris, France.

Smestad, G.P. 1998. Molecular level control of donor/ acceptor heterostructures in organic photovoltaic devices. Sol. Energy Mater. Sol. Cells 55:157-178.
Tennakone, K., G.R.R.R.A. Kumara, A.R. Kumarasinghe, P.M.Sirimanne and K.G.U. Wijayantha.1996. Efficient photosensitization of nanocrystalline $\mathrm{TiO}_{2}$ films by tannins and related phenolic substances J. Photochem. Photobiol. A 94: 217-220.

Terahara, N., N. Saito, T. Honda, K. Tokis and Y. Osajima.1990. Acylated anthocyanins of Clitoria ternatea flowers and their acyl moieties. Phytochemistry 29: 949-953.

Tsubomura, H., M. Matsumura, Y. Nomura and T. Amamiya. 1976. Dye sensitised zinc oxide: aqueous electrolyte: platinum photocell. Nature London 261: 402-403.

Watanabe, T., A. Fujishima, O. Tatsuoki and K. Honda.1976. Photoelectro-chemical reactions at a strontium titanate single crystal electrode. Bull. Chem. Soc. Jpn. 49: 355358.

Zhang, Z., P. Chen, T.N. Murakami, S.M. Zakeeruddin and M. Gratzel. 2008. The 2,2,6,6-tetramethyl-1piperidinyloxy radical: An efficient, iodine- free redox mediator for dye-sensitized solar cells. Adv. Funct. Mater. 18: 341.

Hamann, T.W. and J.W. Ondersma. 2011. Dye-sensitized solar cell redox shuttles. Energy Environ. Sci. 4: 370-381. 